\title{
COGNITIVE THEORY IN ACTION: A DISCOURSE ANALYSIS TO A YOUTUBE VIDEO ABOUT TEACHING
}

\author{
Siti Ina Savira \\ Program Studi Psikologi Universitas Negeri Surabaya \\ e-mail: inasavira@yahoo.com
}

\begin{abstract}
Video offers a richer source of data and has been proven to be useful as a primary source of research. A video from Youtube website was used as a primary source for analysis in this paper. This paper is applying a discourse analysis as suggested by Fairclough (2003) about the discourse as a way of representing; how the discourse was used to express and imply the social relation and action, and the belief committed by the user of the discourse. The analysis was aimed to identify teacher's idea of good teaching by comparing it to relevant theories. The analysis found that cognitive-related terms were consistently appearing in the teacher's discourses; therefore, cognitive theories were used to elaborate a deeper meaning of the discourses. It was concluded that good teaching for the teacher was to focus on students' cognitive higher development.
\end{abstract}

Key words: discourse analysis, YouTube video, cognitive theory, good teaching.

Video has become a popular tool in education and social sciences. Video analysis has added a new dimension to research, particularly qualitative research, by providing 'rich' data and allowing natural context to be recorded. Particularly in education, various approach has been used in video analysis, some were focusing on the visual aspect of the video, while some were interested on the descriptive and the discourse used in the video, and others tried to examine the relationship between the many layers of aspects available in video (see Gooding \& Gregory, 2011; Knoblauch, Baer, Laurier, Petschke, \& Schnettler, 2008; Pailliotet, 1995; Preston, 2010; Xiao, Seagull, Mackenzie, \& Klein, 2004).

This paper is aimed to understand how a particular teacher defines good teaching by applying discourse analysis to a video downloaded from YouTube website as a primary source. Good teaching according to Pressley, should be able to guide learner's to achieve 'good thinking skill' (Pressley, 1995). This paper will first discuss about the context surrounding the primary source, particularly to justify its credibility and accuracy, as a source of research, also authorship, and readership of the source. Then the discourse and its definition will be reviewed briefly, and the remaining part of this paper is devoted to analyse the discourses in the video.

\section{The Youtube Website}

The video as the primary source of the present analysis was downloaded from Youtube website. Youtube website allows free video sharing across the world by internet. Although the main purpose behind the creation of this website in 2005 was for entertainment ((Burke, Snyder, \& Rager, 2009), this website has proven to be useful in research as well (see Burke et al., 2009; Gooding \& Gregory, 2011). Some teachers or lecturers would upload their teaching experience as it happens in real-life situation, hoping to attract up to 100 million viewers per day, in order to expand their educational audiences(Burke et al., 2009). However, there are also some drawbacks in using video from YouTube in educational research.

Due to its free access, both for downloading and uploading, users of YouTube video must be aware of its accuracy and credibility (Burke et al., 2009; Gooding \& Gregory, 2011). Therefore, it is suggested that YouTube video for educational or research purpose must be accompanied with as much as information about its credibility, source, link, 
etc. (Burke et al., 2009). Burke, Snyder, and Rager (2009), agreed that although YouTube website is useful to find research sources, it is difficult to find a video among millions of videos that suits the researcher's needs. A significant time must be devoted for searching an appropriate video in YouTube website.

\section{A Review on the Primary Source}

It is evident that video is a useful source in educational research(Maor, 2000), because it is considered as an appropriate tool to overcome the lost of 'context' or 'setting' in data collection that many researchers thought as equally important as the data itself. It is also one main reason for choosing video for this paper. However, it is important to be aware of the 'document realities' before we begin analysing it (Atkinson \& Coffey, 1997). The context, authorship, audience, and the video structure and function will therefore, be discussed.

The video, which was titled 'interactive teaching method' (ITM video), with caption 'Profile of Chandralekha Singh's interactive teaching style', in YouTube website, is about 4 minutes long and taken in two types of setting (Jeremylevy, 2007). The first setting was the natural setting in the classroom where teaching and learning happens, and the second was testimonials where the teacher, and 3 students were talking to the camera about the teaching and learning. With editing technique, the two settings was placed alternately, with the testimonials took most part of the video.

The video was uploaded by a username of jeremylevy on August $27^{\text {th }}, 2007$, who was a registered YouTube up loader since April 12 $2^{\text {th }}$, 2006 and has uploaded more than 70 videos, which mostly related to India culture with various themes, not education in particular. The ITM video was one of the most viewed video in his channel. It is difficult however, to determine the actual 'author' of the video. The 'author' probably thought that the video was showing a 'good teaching'. A similarity of the cultural background between the teacher in the video and the uploader of the video, could somewhat tell the purpose that related to the positive representation of India culture.

The viewers of this video may vary and difficult to identify. However, the fact that the video was titled Interactive Teaching Method could be some sort of a filter of viewers; only those that are particularly interested in that type of videos would likely to search and spend time to watch the video. Some of the viewers were identifying themselves as students, some as teachers, and others as 'going to be a teacher', while the rest of the viewers did not identify themselves.

By August, 2011, when the video was downloaded for the purpose of this paper, 105.008 people have viewed it; 73 people liked it, and one disliked. However, out of 36 comments posted by the viewers of that video, 28 comments were positive, mostly referring it as a 'good video', while the rest were irrelevant comments. That statistic does not include the number of people clicking the upward thumb icon on some of the comments. Clicking the upward thumb icon is an expression of agreeing the comment or statement, while the downward thumb icon means disagreeing or dislike.

The comments posted for this video will not be part of the analysis; however, they are useful to obtain general impression associate to the video, particularly regarding its accuracy and credibility. If the viewers receiving the intended message of the video instead of being misled by ambiguous or misleading information, it means that the video is credible, and if the information provided in the video is true, it means that the video is accurate. Accuracy and credibility of a YouTube video content is important (Burke et al., 2009; Gooding \& Gregory, 2011), and such information can be obtained by the message received by the viewers (Gooding \& Gregory, 2011).

Most of the comments posted by viewers of various backgrounds were 
resonating with what the teacher in the ITM video was saying. For example, although the teacher did not mention explicitly about the method that she was using anywhere in the video, but one of the comment recognized her method as 'constructivism', other mentioned 'scaffolding', which is also a teaching strategies, while some others saying that they were using the same method for different level of education. Other comments described it as 'inspiring', 'insightful' and 'talks a lot of sense'. Therefore, it is likely that the video is credible and accurate.

The ITM video is the primary source of the analysis, which means that it will be treated as a 'text'. Text definition is not limited in written document, but also verbal and visual, could be published or unpublished, and could be those that came from public, private, or even virtual domain (Fitzgerald, 2007). Based on Gidley (2004) description about the source of research, the ITM video is documentary, which was recorded in video format, open-published, because it can be freely accessed and downloaded from the internet, and more likely to be external, because of the way it was presented, which explained what is going on in the classroom to external audiences.

\section{A Review on the Discourse}

Every teacher may have his/her own belief about what is a good teaching. This belief would affect and be reflected in how they direct classroom activities, set the learning objectives, and perceive their role as a teacher. Therefore, it is presumed that the discourse can be used to derive a teacher's belief of good teaching.

Discourse analysis can generally be defined as the study about the use of language within a context (Jacobs, 2010). Fairclough (2003) argues that discourse is a 'way of representing', in which can be explained by three types of text meaning, namely 'action', 'representation', and 'identification'. The discourse analysis framework in this paper are those suggested by Fairclough about the discourse as a way of representing; how the discourse was used to express and imply the social relation and action, and the belief committed by the user of the discourse. These types can be seen in whole text or in small parts of it(Fairclough, 2003).

\section{Applying Discourse Analysis}

In this section, I am going to apply discourse analysis to see how the teacher positioned herself as a teacher with the students, the expectation she had from the students, her description of her teaching approach, and finally, what can be derived from her idea of a good teaching.

\section{Representation of Action and Social Relation}

Action in a text can be seen from how the discourse is used to encourage action from someone else, which implies a social relation (Fairclough, 2003). The teacher, further on will be referred to as Dr. Singh, used the word 'I(5)' or 'me(2d)' to call herself, and 'you(3b)' to refer to the students when explaining about classroom activity. The word 'me(2d)' referred to her as an object, which implied that she gives opportunity for students to empower themselves in the classroom. Positioning herself as an object reflects her willingness to be in a parallel position with her students. She had also used 'we(2e)', which implied a closer relation to the students when talking about what had happened 'last time(1c)' in the classroom. However, a closer look to the verbs that she used, such as 'ask $(9 a, b)$ ', and 'poll(9d)', had made it clear that Dr. Singh was the one that made decision in the classroom, while the students were doing as she told. By doing that, Dr.Singh was taking position as a teacher, while also stated the order of power.

"So let me(5b) ask(9a) you(10a) a few question here, a few question here about the 
stuff that we(2e) covered last time(1c). And again(1d), think (8a) about these questions yourself $(10 \mathrm{~b})$ first and then I'm (5c) gonna ask $(9 b)$ you $(10 \mathrm{c})$ to talk $(9 \mathrm{c})$ to the person next to you(10d). And then I'll(5d) poll(9d) the class $(10 \mathrm{e}) . "$

Telling the students what to do, or using direct instructions, stated her position as the 'director' of the class. Yet, she would used the words 'think $(8 \mathrm{a})$ ' and 'talk $(9 \mathrm{c})$ ' to the students. For comparison, she could have said 'take notes' or 'listen to my explanation', but her choice to use active verbs shows that she sees her students as empowered.

From cognitive theorist point of view, it is important to reduce the load in the working memory to optimize the thinking process, because it is where 'we think'. When the nature of a task is very demanding with high intrinsic load, teacher's instruction is one of important factor that may affect learner's cognitive load (Paas, Renkl, \& Sweller, 2003, 2004; Paas \& Van Merrienboer, 1994). One effective way to reduce cognitive load is to make connection to the schema in cognition. Generating background knowledge may allow learners to check whether they have relevant cues to retrieve important information (Thiede \& Anderson, 2003). That way several information that relevance will be compressed and therefore, reduce the amount of information need to be handled and reduce the load of the working memory (Paas et al., 2003). From the excerpt above, referring to the 'last time' may indicate the teacher's effort to trigger student's memory; it may serve as a cue for learners to activate relevant schema. Some words that teacher use in their instruction can be effective to help students retrieve relevant information from their memory(Bruning, Schraw, \& Norby, 2011).

The goal of this course is to really $(4 \mathrm{c})$ teach $(9 \mathrm{e})$ student(10f) some effective(13) problem solving strategies (11a) and also to help(9f) them develop(12) some logical thinking skills $(11 \mathrm{~b})$ and of course (13a) that has to be done(13b) in the context(14) of teaching $(9 \mathrm{e})$ them(10f) some physics concepts.

There were at least two goals of teacher in the classroom, according to the above explanation. They are, teaching some problem solving strategies(13,11a) and helping students to develop logical thinking skills(9f,12,11b). She made an emphasis by saying 'really(4c)' on the first part, and therefore put order of priority between the two. She also made a distinction between the first and the second goal. The first verb she used was to 'teach $(9 \mathrm{c})$ ', while on the second she used to 'help(9d)'. Such distinction implied the way she perceived students, as both active and passive.

To 'teach' means that students were passive because they needed to be taught. But the students were also active in their learning, because she wanted them to 'think(8a)' and 'talk $(9 \mathrm{c})$ ' to each other. Again, she made a state of power, of being someone with an expertise and seeing the students as amateur, in terms of mastering problem solving strategies and thinking skills.

Learning the problem solving and thinking skill is not the only important thing. Mastering the subject matter is also emphasised in her teaching. In fact, in order to teach an 'effective(13)' problem solving, which supposedly different kind of level than a 'common' problem solving strategy, and develop some thinking skills, a particular way need to be taken. She made an emphasis using 'of course(13a)', and 'has to be done(13b)'; somewhat stated that there is no other way to teach students to master a higher level of problem solving strategy and thinking skills, but to do it within a specific 'context(14)', which was physics. Therefore, she was emphasising that an effective way to encourage the transformation from novice to expert learner is by teaching them some problem solving strategies and help them to develop some logical thinking skills in a 
specific context or subject matter or domain. Her explanation resonates well with the concept of domain-specific knowledge, which makes an expert and a novice learner difference in their problem solving strategy (Bruning et al., 2011).

\section{Representation of Identification}

Representation of identification can be seen by the way Dr.Singh described what she devoted herself into, or what Fairclough (2003) suggests, 'an undertaking, a commitment, a judgment'. The identification of Dr. Singh teaching that can be seen from the discourse, was the way she used the word 'really(4c) teach', 'actually $(4 a, b)$ review', 'have to always(13d) keep monitoring(18b), and 'especially important(13d)', and 'ask questions(28) all the time (13f)'. Those things she emphasised reflect her commitment in doing it and a way of alerting students to take it seriously. From the emphasised words that she used, she demanded engagement, involvement, and commitment, from both her and the students. She was implying that she would appreciate that the teaching or reviewing was not taken for granted.

“...why (3) don't we(2b) actually (4a) review some of the stuff that we(2c) have talked about last time ( $1 \mathrm{~b}$ ) before I (5a) actually(4b) start talking further(7) about Pauli exclusion principle."

I (5e) strongly(4d) believe(17a) that students $(10 \mathrm{~g})$ have to be(13c) [paused] actively(18a) engaged in the learning(28a) process, they $(10 \mathrm{~h})$ have to always (13d) keep monitoring (18b) their own(10i) learning. And $\mathrm{I}(5 \mathrm{f})$ think $(17 \mathrm{~b})$ that especially important(13e) in physics for students to be ask questions(28) all the time (13f), you know, so that they actually(4e) know(12) what they are really $(4 \mathrm{~g})$ understanding $(12 \mathrm{~b}) \ldots$

Representation of identification also seemed to reflect what she valued in teaching and learning, from the way she said 'I strongly believe $(5 \mathrm{e}, 4 \mathrm{~d}, 17 \mathrm{a})$. These values would be reflected in how she direct and deliver her teaching and what she expected from students' learning(28a). She would value 'active(18a)', 'independent(10i)', and 'critical(28)' students.

By saying 'have to always(13d)' and 'all the time(13f)' she also indicated values in engagement and consistency. She would also encourage deeper level of understanding from her students; she wanted students to 'actually(4e)' 'know(12)' what they are 'really(4f)' 'understanding(12b)'. Those would lead to questions how does 'actually know' differs from 'know', and 'really understanding' differs from 'understanding'?

She explained the process of how the differences may appear in students' learning. Dr. Singh argued that asking 'question(28)' would be an effective way for students to be able to differentiate between know and actually know, or between understanding and really understanding. She did not emphasise about 'giving the right answer to a question posed by the teacher', even though she used questioning technique in the classroom. It implied that she believed on the importance of generating question instead of generating answers, because according to Dr. Singh it will help the students to monitor their own learning $(18 \mathrm{~b}, 10 \mathrm{i})$. If the question came from her, while the students generating answer, it means that the teacher is the one who monitors students' level of understanding. Therefore, it is apparent that Dr. Singh encouraging students to be independent in their learning.

The ability to monitor one's own thinking is crucial in learning; it is part of a higher function of cognition, which is metacognition (Zimmerman, 2000, 2002). The purpose of teaching is no longer about the amount of information the learners need to learn, but rather to guide them to be an independent learner. The latter approach led to the development of self-regulated learning theory that claims that self-regulation is 
human's 'most important quality' (Zimmerman, 2000) and places metacognition at the centre of its cyclical system that allows individual to continuously adjust their cognitive strategies and performance. It can be inferred from the excerpt above that Dr.Singh values the development of higher cognitive skill and functioning.

\section{Teaching Approach}

It is apparent from her discourses that her approach of teaching was emphasising the thinking process. Her discourses has been consistently using cognitive-related terms, such as 'think(8a)', 'remember(8b)', and 'thoughts $(21,22)$ ' or asking for confirmation such as 'right?' or if something 'makes sense(33)', or 'understandable(24)' in order to trigger students' thinking. In addition to that, as explained earlier in this paper, her goal was to teach problem-solving strategy and to help students develop logical thinking skills.

Other strategy that she used in her teaching was to ask students to 'talking to each other(20)'. That strategy she believed would encourage students to 'organize their own thoughts(21)', so that the articulation of that thought can be understood by other people(24).

And $\mathrm{I}(5 \mathrm{~g})$ also believe $(17 \mathrm{c})$ that students can learn a lot by talking to each other(20), because when students are talking to each other it gives...gives them an opportunity to first of all, organize their own thoughts (21) because when you have to, you know, articulate your thoughts (22), you better actually be clear(23) about what you want to say to other people, you know, in order to make it understandable (24) to them.

$$
\begin{aligned}
& \text { "...most people remember }(8 b) \text { it } \\
& \text { correctly..." } \\
& \text { "...Does that make sense to everybody( } 33) \\
& \text { because energy is constant to frequency." }
\end{aligned}
$$

In cognitive theory, her teaching approach, for example asking students to talk to each other(20) is similar to a method known as collaborative learning in constructivism. According to constructivism, collaboration is considered as 'a tool for learning' (Bruning et al., 2011), which supports Dr.Singh idea that such technique serve as a chance for students to organize and articulate their thoughts.

Furthermore, the aim in teaching according to constructivism is more about encouraging learners to construct their own meaning in learning and adopting metacognitive skill to judge own understanding (Bruning et al., 2011). In alignment to that, ) suggested that one of important roles of metacognition in learning expertise is to monitor the process of problem solving. It allows learner to make decision whether further learning is necessary or not (Thiede \& Anderson, 2003).

The above theory supports the idea that students are active instead of passive in learning; 'students do not passively learn from explanation but rather actively learn from them' (Pressley, 1995). However, in order to get to higher level of learning, constructivism argues that leaving students to discover their own strategy in learning is inefficient, because students do not always know what is important or what to be found (Pressley, 1995). The same article suggests that providing students with explicit or direct explanation on problem-solving strategies would be a more efficient approach in teaching. Therefore, teacher's instruction plays an important role in guiding students learning(Bruning et al., 2011; Pressley, 1995). That also explained in the dualism of students' position in learning from Dr.Singh perspective; that students are passive and yet, active.

Realizing the importance of encouraging learning expertise within a specific domain, Dr.Singh's strategy was to trigger 'students' knowledge(25a)', which reflects a repertoire of what they 'already know(25b)'. She would use the word 
'remember(8b)', or sent a 'memory cue' such as 'last time(1c)' or 'and again(1d)'. Similar to earlier explanation, connecting new information to the available schema would help students to construct learning that is more meaningful, therefore encourage better learning.

Representing a problem within a specific context to generate student's thinking also familiar in her teaching. She would pose a question like 'what do you think will happen?(19b)', 'what do you expect will happen?(19c)' which is also a strategy to teach problem-solving strategy in a context or domain-specific situation.

"So this is the target material from which $\mathrm{X}$-rays are going to be emitted, now what really does happen(19a) ... what do you think will happen(19b), if I have a very very high voltage and know that there is a filament here (pointing at diagram in the slide) and there is vacuum in between here and this region, there's just vacuum. If you close the circuit as soon as you close the switch, what do you expect will happen?(19c)"

Since cognitive-related terms seem to consistently appearing in her discourses about her teaching, it can be concluded that her teaching approach was resonating constructivism theory.

\section{AMessage for Fellow Teachers}

$\underline{\text { You }}(29)$ can only $\underline{\text { stretch}}(9 \mathrm{f}) \underline{\text { students' }}$ knowledge(25a) a little bit beyond what they (30a) already know (25b). And so the thing is we(26a) have to always(13g) be very $(13 \mathrm{~h})$ aware $(27 \mathrm{a})$ of where the students $(30 \mathrm{~b})$ are at the particular time on an average so that we(26b) can actually target(31) our instruction just a little bit above that and then a little bit above that, and a little bit above that.. It is particularly important that we(26c) keep in mind (27b) what students $(30 \mathrm{c})$ already know $(25 \mathrm{c})$ and how we $(26 \mathrm{~d})$ can stretch $(9 \mathrm{~g})$ their knowledge(25d) and make them come to exactly(13i) where we(26e) want(9h) them(30d) to be at the end of the course(32).

Focus should be on learning by students (35) not on really teaching by instructors (36), you know like, always (37) have to be how can Imaximize the learning (38).

This part of discourse is a bit different from the rest. Here, the word 'we $(26 a, b, c)$ ' is no longer referring to her and her students, but rather as teachers in general. When she said 'you(29)' she was not talking to the students, in fact she referred the students as 'they(30a)'. Therefore, this part of discourse seems to be dedicated to fellow teachers as she explained what she believes teachers must do, reflected from the way she changed her position against the students.

Although it is dedicated to teacherviewers, Dr.Singh consistently using cognitive-related terms such as 'aware(27a)', and 'keep in mind(27b)'. She also emphasised the role of the teachers as someone with power, because they are the one who can develop, or 'stretch(9f)', students' knowledge. Teachers also have monitoring role to what students' have or not yet learn. Dr.Singh reminded teachers to value this monitoring role, since it is the basis to set the learning goal, which will then be reflected in targetting(31) the instruction. It would make a big difference in students' learning, because it will decide whether or not the students reach the learning target, which was described by Dr.Singh as 'where we want them to be at the end of the course(26e,9f,30d,32)'.

\section{A Review on Paper's Limitations}

As mentioned at the beginning of this paper, video analysis offers a wide range of possibility of analysis as a source of research. It allows a complex setting to be recorded in its natural situation. It is difficult, however, to cover all the data available in a video in one 
comprehensive analysis. That, unfortunately, also appeared in this paper. Many aspects of the video, such as visual aspect and part of the discourse, such as testimonials from the students about the teacher's teaching, had to be excluded from the analysis.

A unique context also appeared in this paper, where the primary source was retrieved from YouTube website. The website itself has been under scrutinized by many researchers to argue on its credibility as a source to collect data or information for a research. It was difficult to identify the real author or the real identity of the up loader, the purpose of the making of the video, and the degree of 'intervention' on the setting. However, viewers' response can provide valuable and useful information about the video. I found it to be an interesting source of information.

Other limitation came from the writer's personal factor. Discourse analysis requires deep and good understanding of linguistic knowledge. The quality of the analysis would rely on the main researcher ability to recognize and elaborate linguistics aspects in a discourse. Therefore, my weaknesses in linguistic may affect the depth of the analysis.

\section{CONCLUSION}

Students are both active and passive. Students need to be taught, not about declarative knowledge or recalling concepts, but rather how to acquire knowledge, so that they will have a learning skill. Students are also active because they are able to construct their own meaning in learning. Dr.Singh suggests collaborative learning and consistently encouraging students' thinking either by direct instruction or provides them with a problem they have to solve.

Dr. Singh shows an adequate selfconfidence as a teacher and as a director in her teaching. She would repeatedly emphasise her position as an expert and as someone who knows the best way to teach students. Furthermore, her discourses seem to be consistent with cognitive theory and approach in learning. She was very fluent with cognitive-related terms that it sort of becoming a theme in her discourses. She values engagement, commitment, and professional expertise in teaching. Good teaching for her is to focus on students' cognitive higher development on learning.

\section{REFERENCES}

Atkinson, P., \& Coffey, A. (1997). Analysing documentary realities. In D. Silverman (Ed.), Qualitative research: Theory, method, and practice. London: Sage Publications.

Bruning, R. H., Schraw, G. J., \& Norby, M. M. (2011). Cognitive Psychology and Instruction (5th ed.). New Jersey: Pearson.

Burke, S. C., Snyder, S., \& Rager, R. C. (2009). An Assessment of Faculty Usage of YouTube as a Teaching Resource. The Internet Journal of Allied Health Sciences and Practice, 7(1), 1-8.

Fairclough, N. (2003). Analysing Discourse: Textual analysis for Social Research.
London: Routledge.

Fitzgerald, T. (2007). Documents and documentary analysis: Reading between the lines. In A. Briggs \& $\mathrm{M}$. Coleman (Eds.), Research methods in educational leadership and management (2nd ed.). Los Angeles: Sage Publications.

Gooding, L. F., \& Gregory, D. (2011). Descriptive Analysis of YouTube Music Therapy Videos. Journal of Music Therapy, 48(3).

Jacobs, K. (2010). Discourse Analysis. In M. Walter (Ed.), Social Research Methods (2nd ed.). Sydney: Oxford University Press. 
jeremylevy. (2007). Interactive Teaching Method (pp. 4 minutes): Youtube website.

Knoblauch, H., Baer, A., Laurier, E., Petschke, S., \& Schnettler, B. (2008). Visual Analysis. New Developments in the Interpretative Analysis of Video and Photography. [Online Journal]. Forum: Qualitative Social Research, 9(3).

Maor, D. (2000). Video Analysis: Adding Another Dimension to Qualitative Research? Paper presented at the Annual Meeting of the American Educational Research Association New Orleans.

Paas, F., Renkl, A., \& Sweller, J. (2003). Cognitive load theory and instructional design: Recent development. Educational Psychologist, 38(1), 1-4.

Paas, F., Renkl, A., \& Sweller, J. (2004). Cognitive Load Theory: Instructional implications of the Interaction between information structures and cognitive architecture. Instructional Science, 32(1), 1-8.

Paas, F., \& Van Merrienboer, J. J. G. (1994). Variability of worked examples and transfer of geometrical problem-solving skills: A cognitive-load approach. Journal of Educational Psychology, 85(1), 122-133.

Pailliotet, A. W. (1995). I Never Saw That Before: A Deeper View of Video Analysis in Teacher Education. Journal of The Teacher Educator, 31(2), 138156.

Pressley, M. (1995). Introduction: good thinking, good teaching, and alternative ways of studying good thinking and good teaching. In M. Pressley \& C. McCormick (Eds.), Cognition, teaching, and assessment (pp. 1-24). New York: Harper Colling College Publishers.
Preston, M. D. (2010, Jan-Feb 2010). Examining Student Thinking through Video Analysis. Educational Technology Magazine 50, 23-27.

Sternberg, R. J. (1998). Metacognition, abilities, and developing expertise: What makes an expert student? Contemporary Educational Psychology, 28(129-160).

Thiede, K. W., \& Anderson, M. C. M. (2003). Summarizing can improve metacomprehension accuracy. Contemporary Educational Psychology, 28, 129-160.

Xiao, Y., Seagull, F. J., Mackenzie, C. F., \& Klein, K. (2004). Adaptive Leadership in Trauma Resuscitation Teams: A Grounded Theory Approach to Video Analysis. Cogn Tech Work, 6(April 20,2004), 158-164. Retrieved from doi:10.1007/s10111-004-0157-z

Zimmerman, B. J. (2000). Attaining selfregulation: A social cognitive perspective. In B. J. Zimmerman \& D. H. Schunk (Eds.), Handbook of selfregulation. San Diego: Academic Press.

Zimmerman, B. J. (2002). Becoming a selfregulated learner. Theory into practice, 41, 64-70 